\title{
Evaluating the Mechanical Performance Properties of Reclaimed Asphalt Pavement Rejuvenated with Different Rejuvenators
}

\author{
Hasan H Joni ${ }^{1}$ | Rasha H A Al-Rubaee ${ }^{1}$ | Mohammed Kh. Shames ${ }^{2}$
}

\begin{abstract}
Affiliations
${ }^{1}$ Civil Engineering

Department, University of Technology, Baghdad, Iraq

${ }^{2}$ Wasit Governorate Court, Wasit, Iraq

\section{Correspondence}

Mohammed Kh. Shames, ${ }^{2}$ Wasit Governorate Court, Wasit, Iraq

Email:

42377@student.uotechnologv.edu.iq

Received

22-May-2020

Revised

18- June-2020

Accepted

27- June-2020
\end{abstract}

doi:10.31185/ejuow.Vol8.Iss1.154

\begin{abstract}
The importance of sustainability in road construction using and renewing the Reclaimed Asphalt Pavement (RAP) resulting from the reconstruction or periodic maintenance of roads is a challenge that requires the use of regenerative additions to restore the characteristics of the old bitumen in pure rap, in order to improve the performance properties of these renewable mixers. As there are many promising studies in this regard. The objective of this study is to recycle and restore RAP using two types of renovators; Waste Cooking Oil (WCO) and Asphalt Cement (AC (85-100)). Five percentages $(1,1.5,2,2.5$ and 3$) \%$ by weight of both types of renovators were added to the RAP, separately, for the purpose of rejuvenation. Marshall Test was performed on the renovated samples to obtain the optimum percentages, which will be adopted in subsequent tests, which include; indirect tensile strength (ITS), tensile strength Ratio (TSR) and Duple Punch Shear Strength Test (DPSST) to evaluate the performance of rejuvenated RAP mixes and compare them with the original RAP. The outcomes indicated that (1.5 and 2.5) $\%$ are the optimal percentages for (WCO and AC (85-100)), respectively. In addition, the results of the performance tests indicated that the renovated RAP mixes are better than the original RAP in terms of stability, temperature susceptibility, stripping resistance and resistance to moisture damage, as well as achieving the specification requirements for the surface course. This indicates that the recycling process is of economic, environmental benefit and industrial sustainability.
\end{abstract}

Keywords: Asphalt cement, RAP, recycled agent, recycled mixture, waste cooking oil.

الخلاصة:إن أهية الاستدامة في بناء الطرق باستخدام وتجديد رصبف الأسفلت المستصلح (RAP) الناتج عن إعادة الإعمار أو الصيانة الدورية للطرق بمثل تحديًا

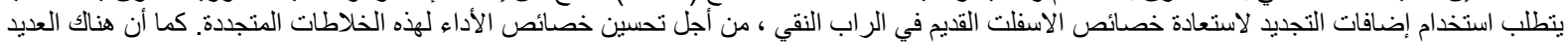

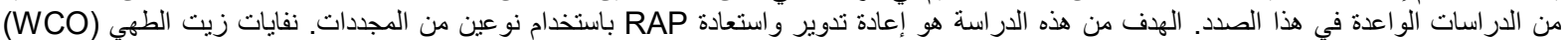

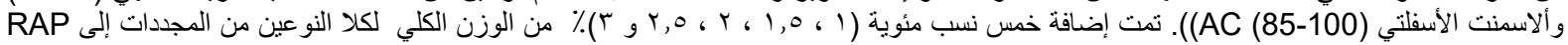

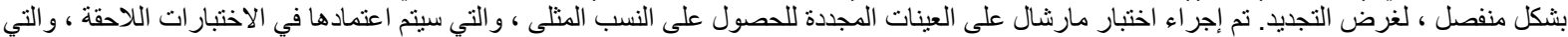

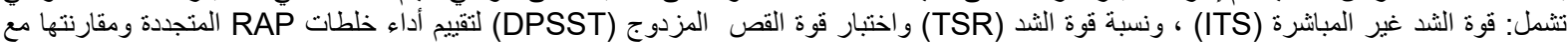

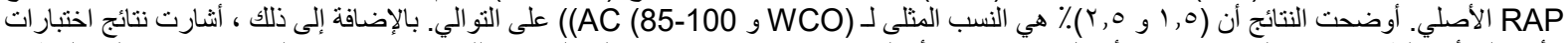

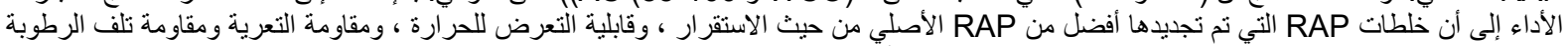

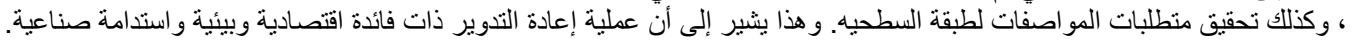

\section{INTRODUCTION}

After several years of traffic loads and climate change, the road will experience aging and reduction its performance. Asphalt aging increases the stiffness of the binder and also affects its physical and chemical properties. Therefore, the aged asphalt cement becomes stiffer and lead to a decrease in the strength of the asphalt while reducing the useful life of the patch, in this case the surfaces of the patch can be milled, which is referred 
to as RAP [1]. Therefore, the main problem arising from the difficulty in using old RAP asphalt paving materials in preparing hot asphalt mixtures is the aging of asphalt, which determines the RAP ratio in the mixture. Therefore, the focus in this study is to find improving additives to recover the properties of old asphalt and benefit from the recycling process using locally available waste in addition to the soft asphalt which is also available locally in the refineries. Moreover, asphalt binder is highly implemented in pavement construction and petroleum is very scares as non-renewable source resulting in the short-term supply and high costs of petroleum asphalt [2]. The recycling of RAP would reduce the costs of pavement construction in addition to environmental benefits. Highways agencies and governments have been encouraged to search for specifications, implement and improve the characteristics of asphalt aging and recycling RAP [3, 4]. In general, the regeneration process should be by increasing the proportion of aromatics in order to improve the susceptibility of the obsolete binder to temperature in addition to increasing the mixture's workability. Thus this method is obtained by increasing the drip strength of the Maltenes stage [5]. The successful use of recycled motor oil (RO) which has made the recycling possible theoretically for the use of WCO as a bitumen regenerator, the novelty of this article is the use of (WCO) as a regenerator in aged bitumen. In general, residual cooking oil (RCO), also called used cooking oil (UCO) or nonedible oil or waste (WCO), is collected in restaurants, food industries, single-use household items and centres, recycling by approved companies [6]. Large quantities of illegally used cooking oil are dumped into landfills and rivers, leading to pollution. The process of using WCO is a big challenge due to the problems caused by collecting and pouring, which leads to contamination of land and ground water resources. [7] For the purpose of using RAP in road construction, lost properties of oxidized asphalt should be recovered using regeneration technology. There are many technologies to overcome RAP hardness, including the use of smoother asphalt, [8]. Moreover, soft asphalt is locally available in refineries such as (AC (85-100)) which has been used in this research paper for RAP regeneration.

The purpose of this research is to investigate the probability of recycling the RAP for the purpose of re-using in pavement construction by renovating it with two types of regenerators: Waste Cooking Oil (WCO) and Asphalt Cement (AC (85-100)) penetration grade and clarifying the effect of these recycling additives on performance properties of RAP.

\section{USED MATERIAL}

\subsection{Reclaimed Asphalt Pavement (RAP)}

The samples of asphalt mixture were brought by the rubblization of asphalt concrete (surface layer) for highway segment of Wasit-Iraq in cooperation with the Directorate of Roads and Bridges of Wasit province. The aged mixture was heated, and three samples were taken and subjected to an ignition test according to the (AASHTOT308) procedure [9]. Table (1) shows the content of the aged binder after the ignition test in addition to the physical properties of the old mixture (RAP) before the recycling process.

Table1. Physical characteristics of old mixture (RAP)

\begin{tabular}{|c|c|c|c|}
\hline Material & Property & Value & Formula limit \\
\hline Asphalt binder & Asphalt content & $4.5 \%$ & $4.9 \%$ \\
\hline \multirow{4}{*}{ Aged mixture } & Stability $(\mathrm{kN})$ & 7.4 & $8 \mathrm{~min}$ \\
\cline { 2 - 4 } & Flow $(\mathrm{mm})$ & 4.8 & $2-4$ \\
\cline { 2 - 4 } & Density $\left(\mathrm{kg} / \mathrm{cm}^{3}\right)$ & 2.187 & ----- \\
\cline { 2 - 4 } & Air void $(\%)$ & 12 & $3-5$ \\
\cline { 2 - 4 } & Gmm & 2.479 & ----- \\
\hline
\end{tabular}

\subsection{Soft $A C(85-100)$}

In this study, asphalt binder of penetration grade (85-100) was used as one rejuvenator. This asphalt was gained from Al-Dora Refinery, south of Baghdad in Iraq. Table (2) shows the physical properties of asphalt according to ASTM procedure (D5, D36, D113, D2170, D 92, D 70 and D 1754 ) [10, 11, 12, 13, 14, 15 and 16], respectively. 
Table2. Physical properties of binder (85-100)

\begin{tabular}{|c|c|}
\hline Property & Results \\
\hline Penetration & 98 \\
\hline Softening point $\left({ }^{\circ} \mathbf{C}\right)$ & 43 \\
\hline Ductility(cm) & $>140$ \\
\hline Viscosity (mPa s) at 135 & 307 \\
\hline Specific gravity & 1.03 \\
\hline Flash and fire point( $\left.{ }^{\circ} \mathbf{C}\right)$ & $273-280$ \\
\hline Loss of weight (\%) & 0.1 \\
\hline Retained penetration of residue $\%$ & 91 \\
\hline Ductility of Residue & $>120$ \\
\hline
\end{tabular}

\subsection{Waste Cooking Oil (WCO)}

The waste cooking oils (WCO) implemented in this research was accumulated from various restaurants and households. The WCO was sieved through a No. 200 sieve to remove any particles, and tested for specific gravity, viscosity, and water content as exhibited in Table 3. The tests were carried out by the general company for food products-Baghdad, by using a Brookfield viscometer for viscosity, a KERN moisture analyzer for water content and a Bingham pycnometer for specific gravity.

Table3. Properties waste oils (WCO)

\begin{tabular}{|c|c|}
\hline Tests & WCO \\
\hline Viscosity (CP) & 156 \\
\hline Specific Gravity & $\mathbf{0 . 9 2}$ \\
\hline Water content (\%) & $\mathbf{0 . 3 1}$ \\
\hline
\end{tabular}

\section{LABORATORY WORK}

\subsection{Sample Preparation}

Samples were prepared for the old mixture $100 \%$ of RAP according to (ASTM D1559, 2015) [17] after heating it in the oven at $(140-160){ }^{\circ} \mathrm{C}$ for $(1-2)$ hours to increase the workability of the aged mixture. Prepared samples were subjected to Marshall Test to gain the properties of the mixture. On the other hand, other Marshall samples were prepared for recycled mixtures of (RAP) with regenerative agents (WCO, Soft AC (85-100)) at( $1 \%, 1.5 \%, 2 \%, 2.5 \%$, and $3 \%$ ) of total weight of RAP , Taking into account the heating of the components separately before mixing at a temperature $(130-160)^{\circ} \mathrm{C}$. Then, they are mixed together for two minutes to ensure a good coating of the aggregate, depending on the visual inspection of the components during the mixing period. Moreover, the Marshall samples of the rejuvenated RAP were used to find the optimum content of these generators based on the Marshall properties for surface layer. Finally, samples of recycled mixtures with the optimum content of regenerative agents were subjected to other tests such as: indirect tensile strength at $(25,40 \text { and } 60)^{\circ} \mathrm{C}$, moisture damage and double punch shear strength test.

\subsection{Tests}

\subsubsection{Marshall Test}

In this test, firstly the bulk specific gravity of each specimen, theoretical specific gravity (maximum) and percentage of air void according to ASTM (D2726-08, D2041-03 and 3203-05) [18, 19 and 20] respectively, were calculated. Also Marshall Stability and flow were conducted for each sample according to (ASTM D1559, 2015) [17] in order to find the optimum content for regenerating agents. Secondly, the optimal content of the regenerative agents in this study were used to prepare new Marshall samples and were subjected to other tests.

\subsubsection{Indirect Tensile Strength Test (ITS)}

To assess the indirect tensile strength of renovated mixes using the optimum content of regenerative agents (WCO and fine AC (85-100)) specified in this paper according to procedure (ASTM D6931-07) [21]. The final results of the test were obtained from the average value of three samples each per temperatures $(25,40 \text { and } 60)^{\circ} \mathrm{C}$. Figure 1 illustrates the test mechanism. 


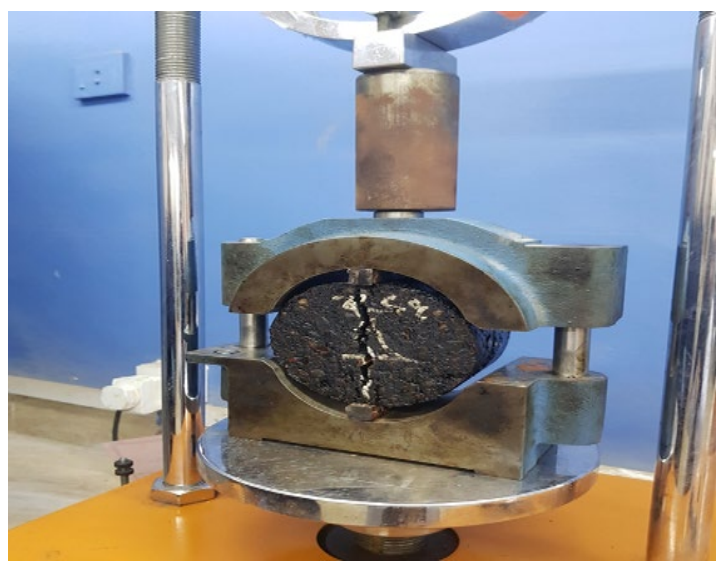

Figure 1 ITS test devises

\subsubsection{Indirect Tensile Strength Ratio Test}

Moisture resistance test has been conducted according to (ASTM D4867, 2015) [22] for original and recycled RAP. A group of six samples was prepared for each regenerative agent, where the samples were divided and subjected to different conditions. Three specimens were subjected to the indirect tensile strength test after storing them in a water bath at temperature of $(25){ }^{\circ} \mathrm{C}$ for a period of $(60-120)$ minutes, and the average of the three unconditioned specimens tested by (ITS) were calculated. On the other hand, the remaining three samples were adapted by placing them in a volumetric container $(4000 \mathrm{ml})$ of heavy glass and filled with water at temperature $(25)^{\circ} \mathrm{C}$, with running the vacuum with a capacity of $3.74 \mathrm{kPa}(28 \mathrm{Mm} \mathrm{Hg})$ for a period of (5-10) minutes to obtain the saturation level (55-80) \%. The saturated samples were subjected to deep freezing at $(-18){ }^{\circ} \mathrm{C}$ for a period $(16)$ hour, followed by storing the samples in a water bath at $60^{\circ} \mathrm{C}$ for 24 hours according to the test requirements. Before the test is carried out, the samples are placed in another water bath at a temperature of $25^{\circ} \mathrm{C}$ for an hour. Finally, the samples were tested to find indirect tensile strength of the samples and calculate the average value. Figure 2 shows the steps for examining the samples.
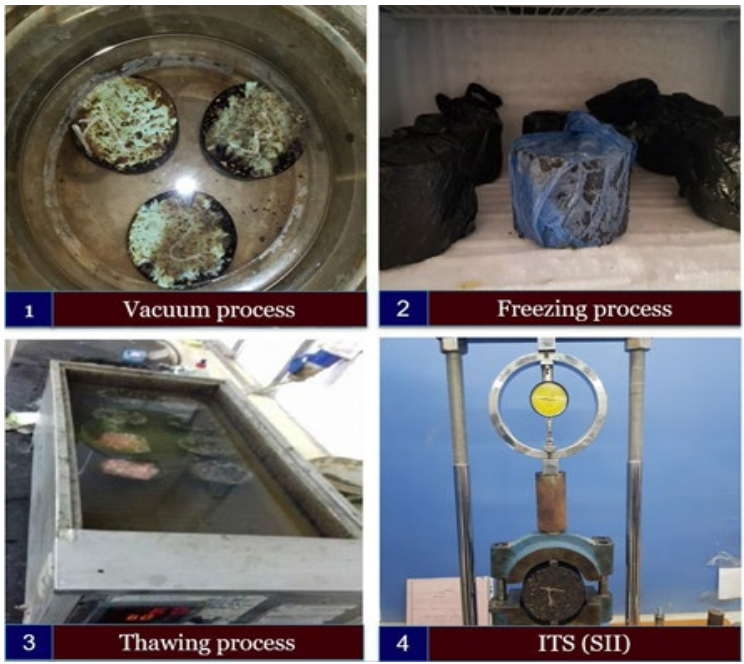

Figure 2 Specimens conditioning for TSR test

\subsubsection{Double Punch Shear Test (PSS)}

This test procedure was previously developed by the University of Arizona (Jimenez 1974) [23]. The Scientist Jimenez used this test to measure bitumen stripping. Three Marshall Samples (per each regenerative additive) were used in this test and adjusted by placing them in a water bath at $60^{\circ} \mathrm{C}$ for 30 minutes. The test was carried out by centrally loading the cylindrical sample with two cylindrical punches located at the top and bottom of the sample, with the sample centred between the two punches $(2.54 \mathrm{~cm}$ diameter $)$ and perfectly aligned and then loaded at a speed of $2.54 \mathrm{~cm} / \mathrm{min}$ until it broke as shown in figure 3. Meter reading is recorded at the highest load resistance till the specimen fails. Several studies have reported this test [24, 25, 26, and 27]. 


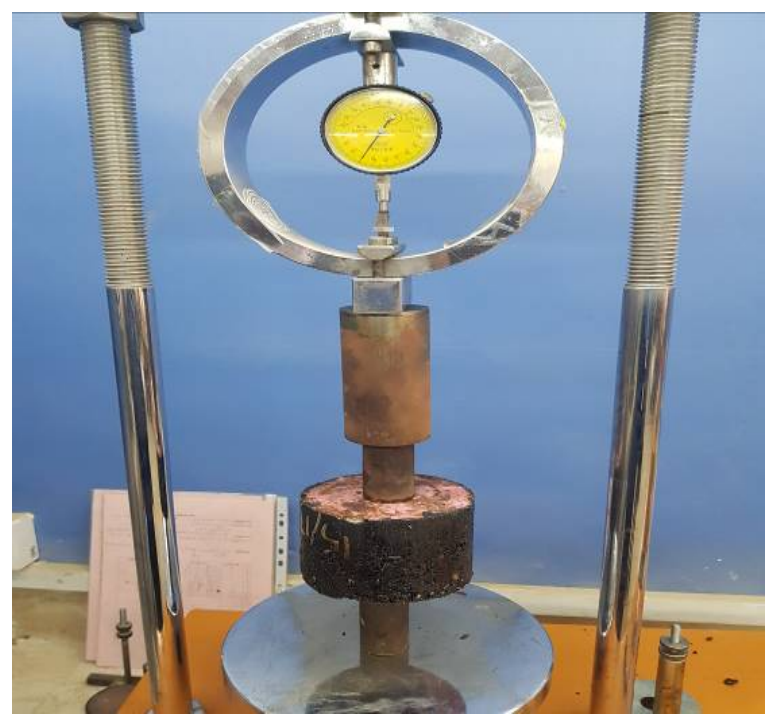

Figure 3 Double punch test device

\section{RESULTS AND DISCUSSION}

\subsection{Marshall Properties}

\subsubsection{Bulk density}

Figure 4 shows the bulk density of recycled mixtures and the old mixture (RAP). The low density of the old mixture at $(2.18 \mathrm{~g} / \mathrm{cc})$ indicates the lower operability of the mixture due to the high viscosity resulting from the asphalt aging in (RAP), which reduces the susceptibility of the samples to compaction, in addition to increasing the percentage of air voids inside the mixture. Whereas, recycled mixtures using regenerative additives (WCO and $\mathrm{AC}(85-100)$ showed an increase in bulk density by $(9.2 \%$ and $7.8 \%)$ for regenerative additives (WCO and AC (85-100)) respectively, compared to the RAP mix. The reason for this may be due to the restoration of the equilibrium ratio (asphaltenes/ maltenes) in recycled mixtures, unlike the aging mixture.

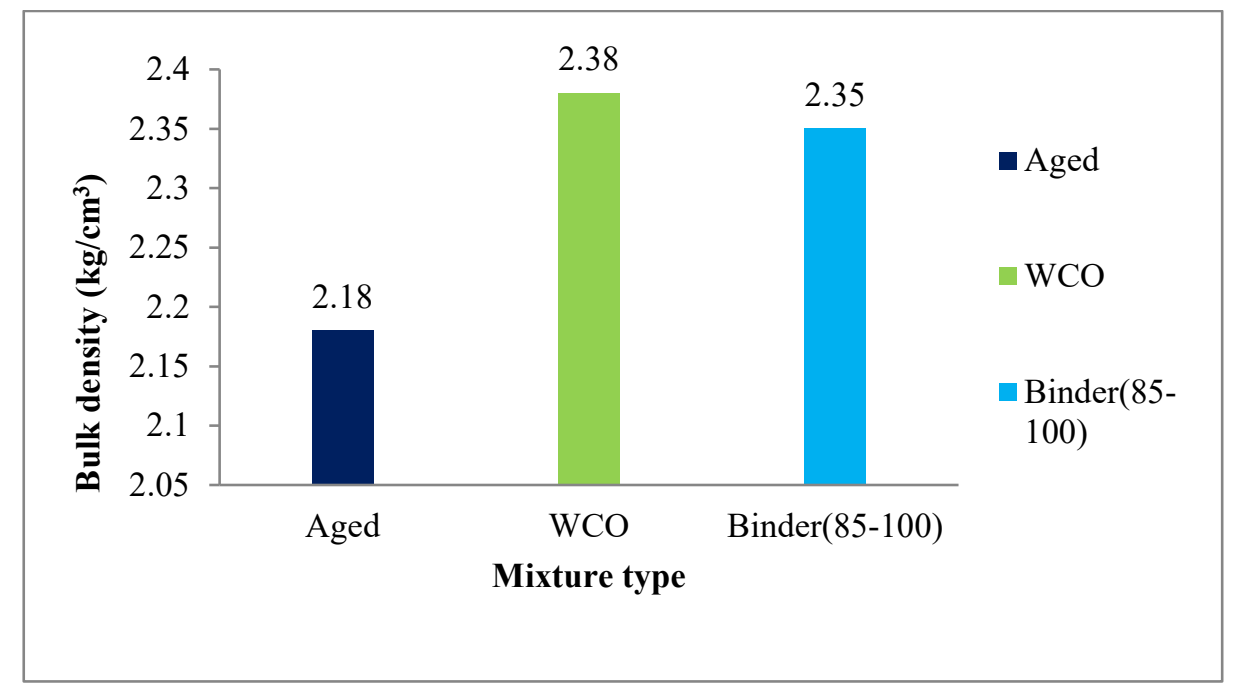

Figure 4 Bulk density for aged and recycled mixture

\subsubsection{Marshall Stability}

Figure 5 shows that the stability value resulting from testing the aged mixture sample is less than the stability values of the recycled mixtures due to the aging of the bonding material and the increase in the air void ratio in the RAP, while the regenerators played a positive role in restoring the properties of the bitumen thereby raising the workability and adhesion of mix components. The stability value of the aged mixture was low at $(7.42 \mathrm{kN})$, but it increased by $(34.8 \%$ and $106 \%)$ for the mixtures recycled with (WCO, and AC (85-100)) respectively, in comparison with the aged mixture. This the result agrees well with [28]. 


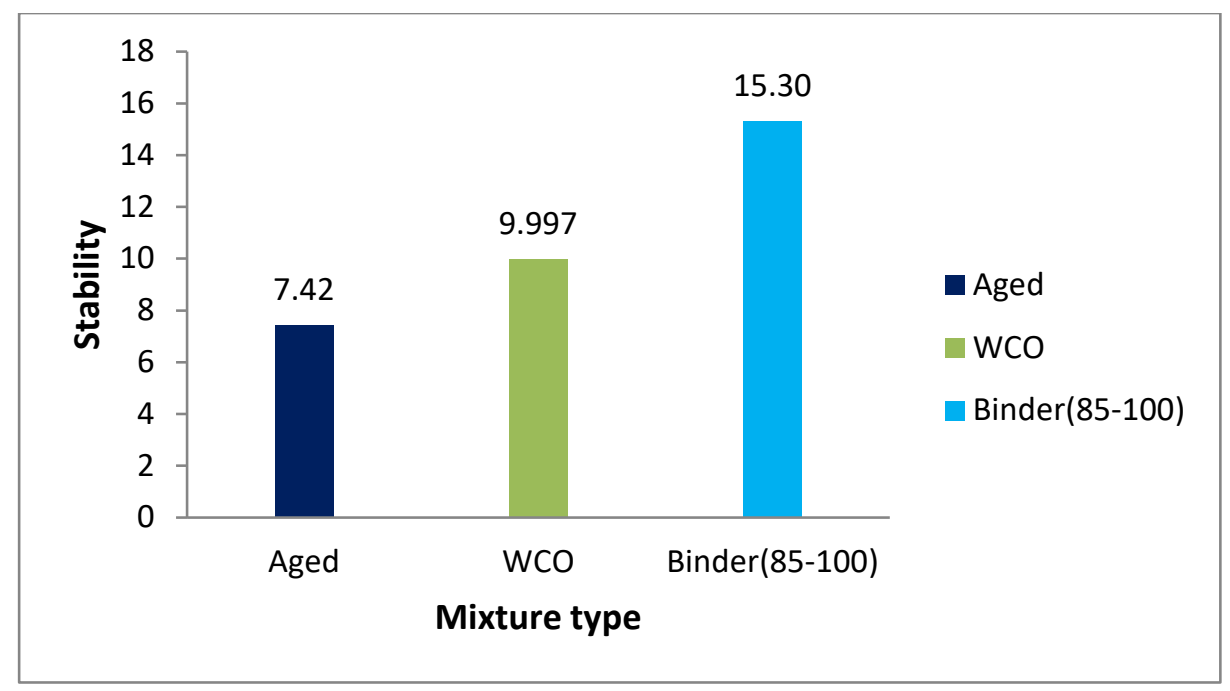

Figure 5 Marshall Stability result for old and recycled mixture

\subsubsection{Marshall Flow}

Figure 6 shows the outcomes of the flow property of renovated mixtures using regenerative additives and aged mixture (RAP). As shown in Figure 6, there is a decrease in the value of Marshall flow of recycled mixtures compared to the old mixture. Moreover, all kinds of renovated mixtures meet the flow limits of the surface layer at (2-4) $\mathrm{mm}$. On the other hand, it was noted that recycling using the regenerative agent (AC (85-100)) gave the higher flow rate than WCO-Rejuvenated RAP, indicating a difference in viscosity between regenerating additives and its role in the recycled mixture.

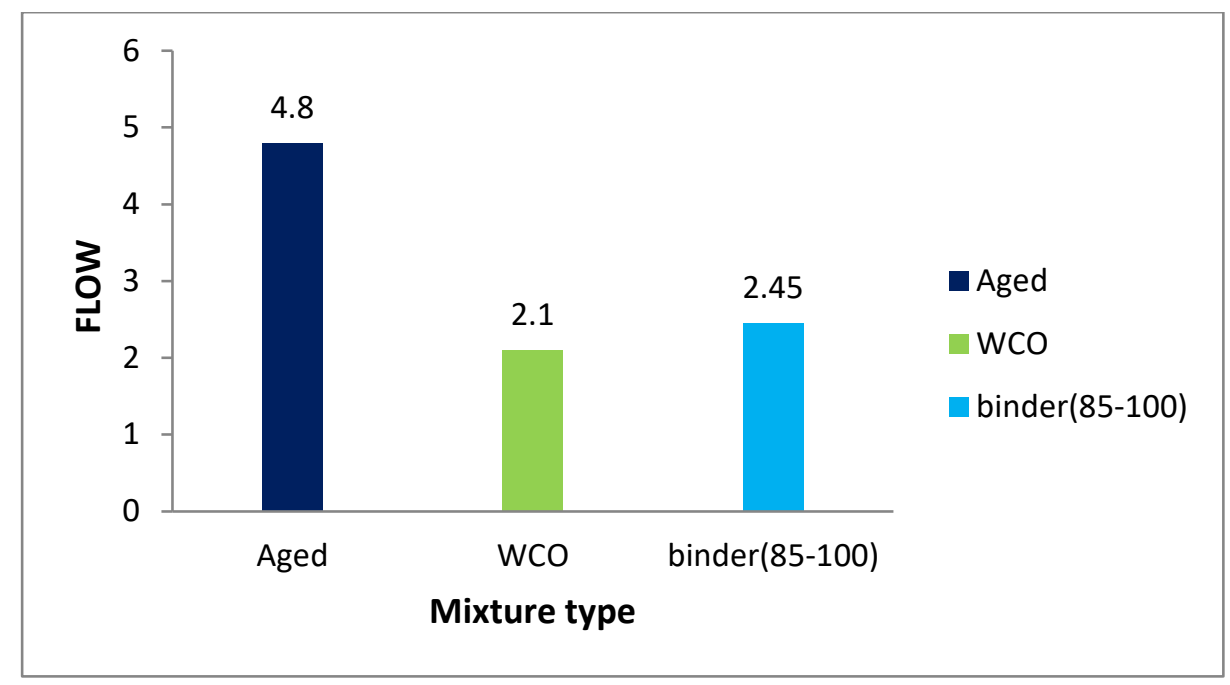

Figure 6 Marshall Flow for aged and recycled mixture

\subsubsection{Percentage of Air Voids}

Figure 7 shows the percentage of air voids for the recycled mixtures and the aging mixture. As shown in the figure, there is a significant reduction in the percentage of voids at $(72.5 \%$ and $68.3 \%)$ for regeneration additives (WCO and AC (85-100)), respectively, compared with the old mixture. This indicates that the recycling process has a prominent role in enhancing the volumetric properties of the rejuvenated aged mixture using the waste additives established in this paper. This corresponds well with a number of researchers [29, 30, and 31]. 


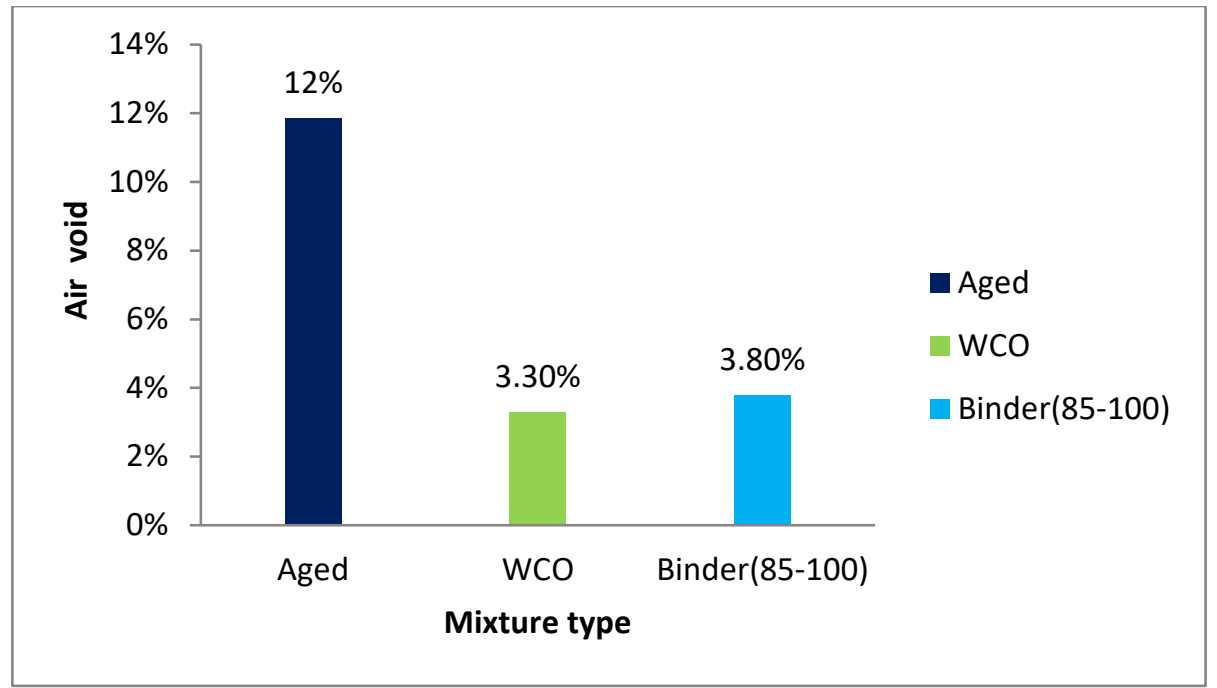

Figure 7 Air Void for Aged and Recycled mixture

Depending on marshal results, the optimum contents for the used rejuvenators were (1.5 and 2.5) \% for WCO and AC (85-100) respectively. These contents were used in preparing Marshal samples in order to be tested for the other performance tests.

\subsection{Effect of renewals agent types on indirect tensile strength (ITS)}

The samples were subjected to the indirect tensile strength test at $(25,40$ and 60$){ }^{\circ} \mathrm{C}$ according to (ASTAM D6931, 2015) [20]. Where three samples were tested for each original and recycled mixtures at (optimum content). The mean values were calculated to represent the indirect tensile strength of the each mixture type at the specified temperature. The recycling process by the AC (85-100) revealed a rise in the value of the indirect tensile strength (ITS) at a temperature of $25{ }^{\circ} \mathrm{C}$. The value of the increase in the mixtures recycled using AC (85-100) was (191.6\%), while the regenerated mixtures with oils (WCO) gave a percentage of decrease of (39\%), in comparison with the RAP mixture. This can be attributed to the lower viscosity of the regenerative additive (WCO) and the lower content in the mix as shown in Figure (8)

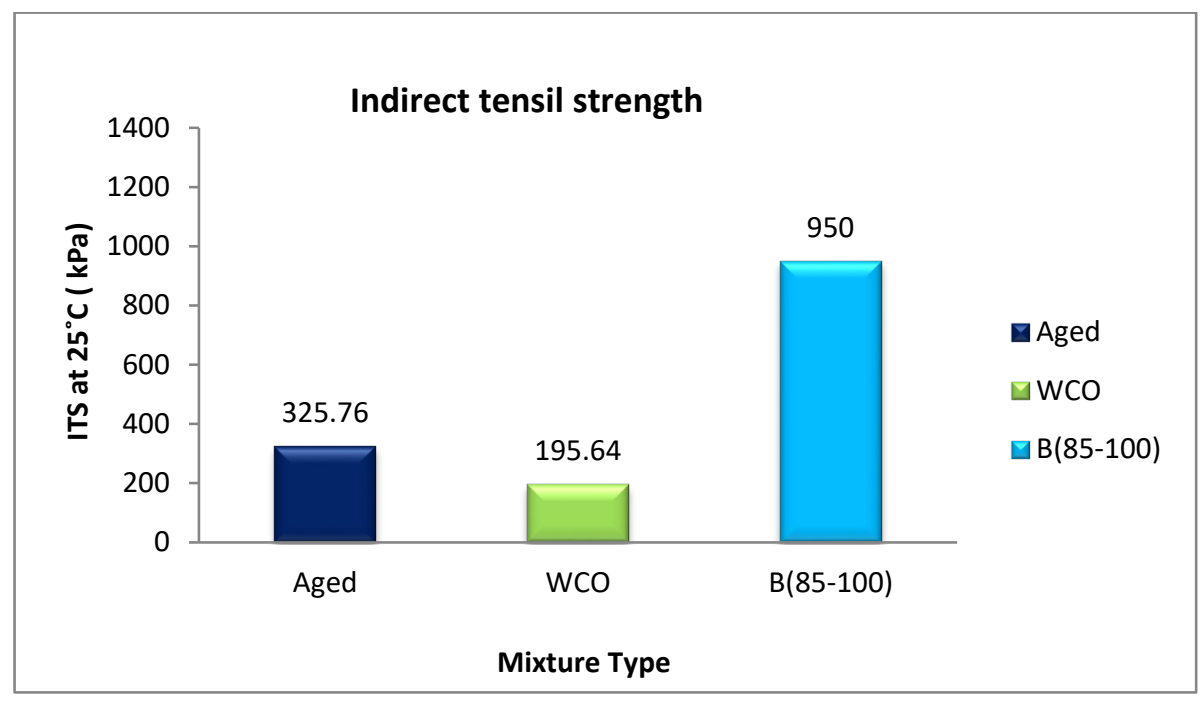

Figure 8 ITS results for aged and recycled mixture at $25^{\circ} \mathrm{C}$

At $40{ }^{\circ} \mathrm{C}$, as shown in Figure 9, the value of (ITS) for mixtures recycled using WCO is $44 \%$ less than the old mixture, due to the lower content of the regeneration additive, low viscosity of higher temperature and other properties of the oil, while the value of ITS for the old mixture was lower in comparison with the indirect tensile strength of the recycled mixture using (AC soft (85-100)) by (108.9\%), and this decrease is due to the increase in the ratio of air voids in the old mixture, lower apparent density and gradual increase at temperature, therefore, the aging mixture does not have sufficient resistance to withstand the force applied. Figure 9 shows the (ITS) value of the age and recycled mixtures. 


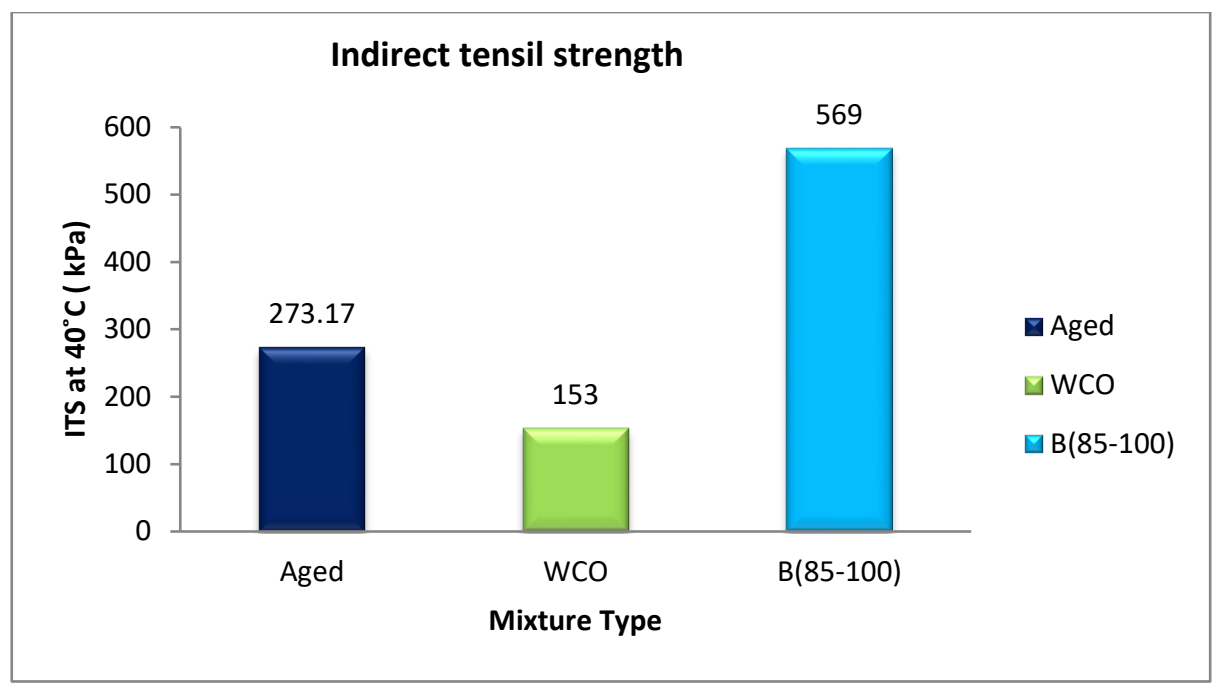

Figure 9 ITS results for aged and recycled mixture at $40{ }^{\circ} \mathrm{C}$

Moreover, the percentage of the decrease in the value of (ITS) for recycled mixtures with (WCO) was about (19.7\%) compared to the old mixture, as shown in Figure (10) below at $\left(60^{\circ} \mathrm{C}\right)$. Whereas, the recycled mixtures with AC (85-100) revealed the highest value of indirect tensile strength compared to other recycled and the old mixtures.

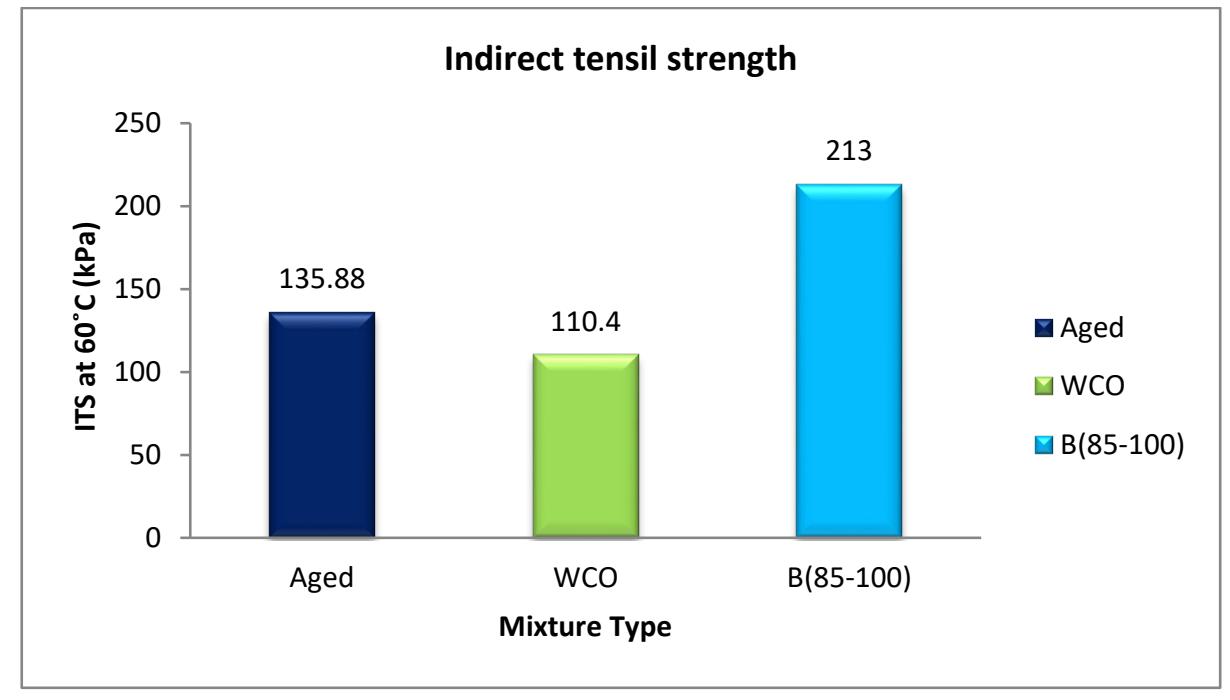

Figure 10 ITS results for aged and recycled mixture at $60^{\circ} \mathrm{C}$

Also, it can be noted from figurs $(8,9$, and 10$)$ that the WCO-rejuvenated RAP have less temperature susceptibility compared to original and AC (85-100)-rejuvenated RAP.

\subsection{Effect of renewals agent types on tensile strength ratio (TSR)}

The outcomes of the tensile strength ratio test showed that regenerated mixtures using regenerative agents (WCO and soft AC) had a high resistance to moisture damage since the TSR values for these mixtures were greater than $(80 \%)$ which represents the minimum specifications requirements as shown in Figure 11 . As can be seen from Figure 11 the values of (TSR) of the regenerated mixtures with (WCO, AC (85-100)) at the optimum ratios above the value (TSR) of the original RAP mixture. It is possible to explain the reason for this rise in the resistance to moisture damage after the regeneration process to the decrease in the percentage of air voids and the improvement of aggregate coating in addition to increasing the cohesion and adhesion between the components of the mixture and obtaining a well-compacted mixture, and thus a high density of the recycled mixture, and this is similar to the results obtained by a number of researchers [27, 28, 30, and 32]. 


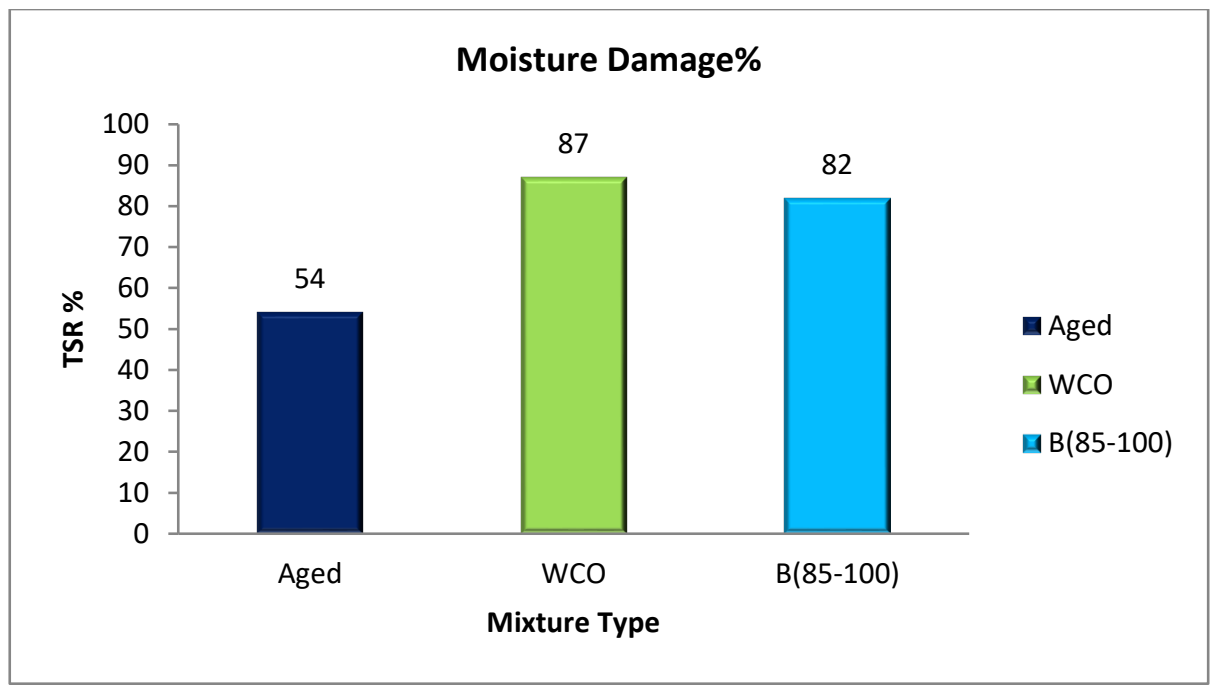

Figure 11 TSR results for aged and recycled mixture

\subsection{Effect of Renewals Agent Types on Double Punching Shear Strength (PSS)}

Figure 12 shows the results of a double shear strength test for the aging mixture and the regenerated mixtures using (WCO and soft AC(85-100)). As can be seen from Figure 12, the value (PSS) of the aging mixture is less than renovated mixtures. This may be due to the low density and the increased air voids resulting in less cohesion of mixture components for the original RAP. It was also noticed that the recycled mixture with fine asphalt showed a higher value of (PSS) compared to the old mix (RAP). The percent of increase rate was about (185\%) for the soft AC regeneration additive (85-100), while the results of the double-hole strength of the recycled mixture using oil waste confirmed a slight increase compared to the aging mixture, but less than the values resulting from recycling using soft asphalt, Where the increase rate was at (28\%), and therefore, these results showed the positive impact of the recycling process on aged asphalt mixtures (RAP), and this leads to economic and environmental benefits, in addition to preparing promising future programs for the renewal processes.

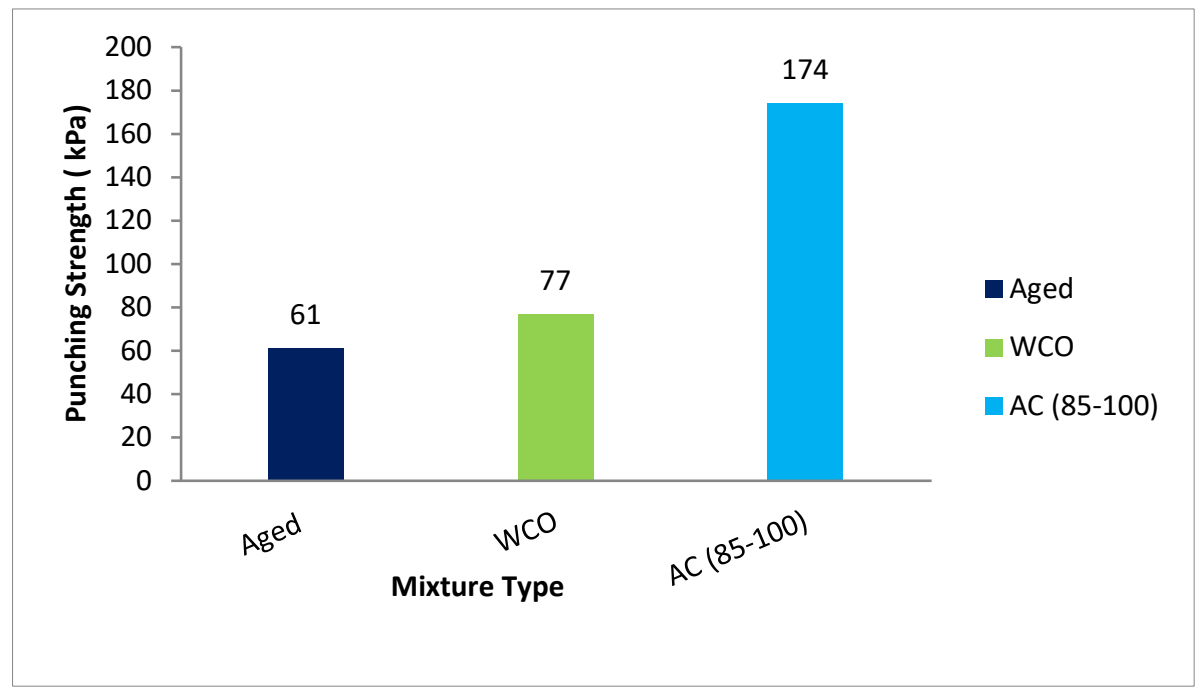

Figure 12 Double Punch test results for aged and recycled mixture

\section{CONCLUSIONS}

The following conclusions were obtained from the current study results:

1- The optimum ratio of the recycling agents content for two types of regenerative additives was $(1.5 \%$ and $2.5 \%$ ) of the total weight mix For (WCO and Soft AC (85-100)) respectively.

2- The optimum ratio of the recycling additive (WCO) was lower than the optimum ratio of the recycling additive (AC (85-100)) used in this study which is due to lower viscosity of WCO compared to AC (85100). 
3- The addition of the rejuvenators improved the stability of Marshall, and other characteristics of the mixtures. The improvement rate of Marshall's stability to recycling factors (WCO and fine AC (85$100)$ ) was $(35 \%$ and $106 \%)$, respectively.

4- The use of soft asphalt (85-100) in regeneration and recycling of RAP gave better performance results compared to oil residue due to the different physical properties.

5- The Marshall Flow values for the renovated samples were within the specifications standards and they were less than the value of the original RAP.

6- The rejuvenation with both types of renovators led to a decrease in the percentage of volume of air voids compared to the old mixture.

7- The results of ITS for original and the rejuvenated samples showed that the WCO-rejuvenated RAP have less temperature susceptibility compared to original and $\mathrm{AC}(85-100)$-rejuvenated RAP. However, AC (85-100)-rejuvenated RAP showed higher strength compared to original and WCO-rejuvenated RAP.

8- The rejuvenation with both WCO and AC (85-100) had enhanced the resistance to moisture damage of the RAP. However, WCO gave better effect compared to AC (85-100).

9- The addition of both WCO and AC (85-100) increased the stripping resistance of RAP with better effect of AC (85-100) in comparison with WCO.

10- Finally, it can be concluded that the rejuvenation of RAP with WCO and AC (85-100) is applicable and can affect positively towards the economic and the environmental.

\section{RECOMMENDATIONS}

For future works, it is suggested to investigate the effect of using other types of waste oils and other grades (softer grades) of asphalt binder as rejuvenators as well as utilizing warm additives. Furthermore, other properties like fatigue and thermal cracking resistance are needed to be investigated.

\section{ACKNOWLEDGMENTS}

The researchers would like to thank the University of Technology, workers in the asphalt lab and the project management department in Wasit Governorate, Iraq.

\section{REFERENCES}

1. Joni H, Al-Rubaee H, \& Al-zerkani A, (2019). Rejuvenation of aged asphalt binder extracted from reclaimed asphalt pavement using waste vegetable and engine oils. Case Studies in Construction Materials, 11, e00279.

2. Joni H, \& Al-Rubaee R, \& Ali M, (2020). Characteristics of asphalt binder modified with waste vegetable oil and waste plastics. IOP Conference Series Materials Science and Engineering. 737. 10. 10.1088/1757-899X/737/1/012126.

3. Widyatmoko I, (2008). Mechanistic-empirical mixture design for hot mix asphalt pavement recycling. Construction and Building Materials, 22(2), 77-87.

4. Shen J, Amirkhanian S, \& Tang B, (2007). Effects of rejuvenator on performance-based properties of rejuvenated asphalt binder and mixtures. Construction and Building Materials, 21(5), 958-964.

5. García Á, Schlangen E, van de Ven M, \& Sierra-Beltrán G, (2010). Preparation of capsules containing rejuvenators for their use in asphalt concrete. Journal of hazardous materials, 184(1-3), 603-611.

6. Singhabhandhu A, \& Tezuka T, (2010). The waste-to-energy framework for integrated multi-waste utilization: Waste cooking oil, waste lubricating oil, and waste plastics. Energy, 35(6), 2544-2551.

7. Math C, Kumar, P., \& Chetty, V, (2010). Technologies for biodiesel production from used cooking oilA review. Energy for sustainable Development, 14(4), 339-345.

8. Im S, Karki P, \& Zhou F (2016). Development of new mix design method for asphalt containing RAP and rejuvenators. Construction and Building Materials, 115, 727-734.

mixtures

9. Standard A. A. S. H. T. O. (2009). T308: Standard Method of Test for Determining the Asphalt Binder Content of Hot Mix Asphalt (HMA) by the Ignition Method. Standard specifications for Transportation Materials and Methods of Sampling and Testing

10. ASTM D5/D5M-19a (2019). Standard test method for penetration of bituminous materials. ASTM International, West Conshohocken, www.astm.org

11. ASTM D36/D36M-14e1 (2014). Standard Test Method for Softening Point of Bituminous Materials (Ring-and-Ball Apparatus).ASTM International, West Conshohocken, PA, www.astm.org 
12. ASTM D113-17 (2017). Standard test method for ductility of bituminous materials. ASTM International, West Conshohocken, PA, www.astm.org

13. ASTM D2170/D2170M-18 2018, Standard Test Method for Kinematic Viscosity of Bituminous Materials ASTM International, West Conshohocken, PA, www.astm.org

14. ASTM D92-18 2018. Standard test method for flash and fire points by Cleveland open cup tester. ASTM International, West Conshohocken, PA, www.astm.org

15. ASTM D70-18a 2018, Standard Test Method for Specific Gravity and Density of Semi-Solid Bituminous Materials (Pycnometer Method). ASTM International, West Conshohocken, PA, www.astm.org

16. ASTM D1754/D1754M-09 201. Standard test method for effects of heat and air on asphaltic materials (thin-film oven test), ASTM International, West Conshohocken, PA www.astm.org

17. ASTM D1559-2015. Standard Test Method for measure Stability and Flow. ASTM International, West Conshohocken, PA, www.astm.org

18. ASTM D2726-08, Standard Test Method for Bulk Specific Gravity and Density of Non-Absorptive Compacted Bituminous Mixtures, ASTM International, West Conshohocken, PA, 2008, www.astm.org

19. ASTM D2041-03, Standard Test Method for Theoretical Maximum Specific Gravity and Density of Bituminous Paving Mixtures, ASTM International, West Conshohocken, PA, 2003, www.astm.org

20. ASTM D3203-05, Standard Test Method for Percent Air Voids in Compacted Dense and Open Bituminous Paving Mixtures, ASTM International, West Conshohocken, PA, 2005, www.astm.org

21. ASTM D6931-07, Standard Test Method for Indirect Tensile (IDT) Strength of Bituminous Mixtures, ASTM International, West Conshohocken, PA, 2007, www.astm.org

22. ASTM D4867/D4867M Standard Test Method for Effect of Moisture on Asphalt Concrete Paving Mixtures

23. Jimenez A, (1974). Testing for Debonding of Asphalt from Aggregates, Transportation Research Record 515, TRB, National Research Council, Washington, D.C., pp. 1-17.

24. Kiggundu M, Roberts L, (1988). Stripping in Hma Mixtures: State-Of-The-Art and Critical Review of Test Methods, National Centre for Asphalt Technology, NCAT Report No.88-2

25. Solaimanian J, Harvey M, Tahmoressi, and Tandon, V, (2004). Test Methods to Predict Moisture Sensitivity of Hot-Mix Asphalt Pavements, Moisture Sensitivity of Asphalt Pavements CD-ROM, Transportation Research Board, National Research Council , Washington, D.C., pp. 77-110.

26. Turos I, (2010). Determining the Flexural Strength of Asphalt Mixtures using the Bending Beam Rheometer. M.Sc. Thesis, University Of Minnesota

27. Sarsam I, (2006). Improving Asphalt Concrete Quality for Ramps and Approaches ." Indian Highways, 34 (3), PP.61- 66

28. Hasan A, (2012). Assessing Performance of Recycled Asphalt Concrete Sustainable Pavement". M.Sc. thesis, College of Engineering, University of Baghdad

29. AL-Shujairy S, (2014). Test Fatigue and Rutting Potentials of Recycled Sustainable Asphalt Pavement. M.Sc. thesis, College of Engineering, University of Baghdad

30. Sarsam and Saleem, (2018). Prospects of Using Liquid Asphalt as Rejuvenation Agent for Asphalt Pavement recycling", submitted to Advancements in Materials, 2, page 64-74,.

31. AL-Taee SH, (2019). Influence of Additives on the Durability of Recycled Asphalt Concrete .MSc. thesis, College of Engineering; University of Baghdad

32. AL-Zubaidi I, (2013). Durability of Recycled Asphalt Concrete Pavement. MSc. Thesis, College of Engineering; University of Baghdad 